\title{
Female gender increases the risk of death during hospitalization for pediatric cardiac surgery
}

\author{
Harry A. Seifert, MD, MSCE, ${ }^{a, b}$ David L. Howard, PhD, ${ }^{c}$ Jeffrey H. Silber, MD, PhD, ${ }^{a, d, e}$ and David R. Jobes, MD ${ }^{a, b}$
}

Objectives: The study objective was to determine whether gender is a determinant of in-hospital mortality after surgery to repair congenital heart disease in patients aged 20 years or less. Secondary objectives were to determine other factors associated with increased risk of death and whether female gender is associated with increased length of stay or total charges.

Methods: The study included a retrospective cohort consisting of all records indicating cardiac operations within the Healthcare Cost and Utilization Project Kids' Inpatient Database for the year 2000. Logistic regression was used to simultaneously evaluate the effect of gender on the risk of death while adjusting for all other factors being considered. Logistic regression was then used to evaluate possible differences in length of stay or total charges.

Results: Female gender was associated with increased risk of in-hospital death when all of the other measured factors were taken into consideration (odds ratio 1.31, 95\% confidence interval 1.02-1.69). Other factors that were significantly associated with increased in-hospital mortality after pediatric cardiac surgery included the number of days between admission and operation; African American race; young age (neonates and infants compared with children aged $\geq 1$ year); pulmonary hypertension; and the Norwood operation. There were no significant gender differences in risk-adjusted length of stay or total charges.

Conclusions: In-hospital mortality after pediatric cardiac surgery seems to be

From the Department of Anesthesiology and Critical Care, The Children's Hospital of Philadelphia, ${ }^{a}$ Philadelphia, Pa; Center for Clinical Epidemiology and Biostatistics, Department of Biostatistics and Epidemiology, University of Pennsylvania School of Medicine, ${ }^{\mathrm{b}}$ Philadelphia, Pa; School of Medicine, Johns Hopkins University, ${ }^{\mathrm{c}}$ Baltimore, Md; Department of Pediatrics, The Children's Hospital of Philadelphia, ${ }^{\mathrm{d}}$ Philadelphia, Pa; Center for Outcomes Research, The Children's Hospital of Philadelphia, ${ }^{\text {e }}$ Philadelphia, Pa.

Received for publication Sept 14, 2006; revisions received Oct 21, 2006; accepted for publication Nov 1, 2006

Address for reprints: Harry A. Seifert, MD, MSCE, Department of Anesthesiology and Critical Care, The Children's Hospital of Philadelphia, Philadelphia, PA 19104 (E-mail: harryaseifert@ comcast. net).

J Thorac Cardiovasc Surg 2007;133:668-75 $0022-5223 / \$ 32.00$

Copyright (๑) 2007 by The American Association for Thoracic Surgery

doi:10.1016/j.jtcvs.2006.11.014 associated with patient gender but not with the type of insurance or ability to access higher-volume pediatric facilities or teaching hospitals.

$\mathrm{D}$ ifferences in outcomes for illness and treatments between males and females are increasingly being recognized. Surgery for heart disease is of particular interest because women have been shown to experience worse outcomes than men after coronary artery bypass surgery. ${ }^{1-3}$ Although this difference in outcomes has been documented in several studies, the underlying reasons remain obscure. Investigators have proposed that gender differences in postoperative outcome are due to a variety of factors, including biologic differences, different use of inpatient services, and poorer social support networks.

It is less clear whether gender affects survival after pediatric heart surgery. Before puberty, hormonal effects are less prominent, but despite this, there is ample evidence that gender differences in mortality and morbidity become apparent early in life. Among chromosomally normal conceptions, males are more likely to be spontaneously aborted than females. ${ }^{4}$ Males are also more likely to be delivered prematurely ${ }^{5}$ and to die from neonatal respiratory distress syndrome, ${ }^{6}$ neonatal neurologic complications, ${ }^{7}$ and birth defects. ${ }^{8}$

Despite this evidence that gender may affect the outcome of disease processes in children, the effects of gender on outcome after pediatric cardiac surgery is uncertain. Numerous studies using data from single centers or combined data from the 


$$
\begin{aligned}
& \text { Abbreviations and Acronyms } \\
& \begin{aligned}
\mathrm{CI} & =\text { confidence interval } \\
\mathrm{DRG} & =\text { diagnosis-related group } \\
\mathrm{HCUP} & =\text { Healthcare Cost and Utilization Project } \\
\mathrm{KID} & =\text { Kids' Inpatient Database } \\
\mathrm{OR} & =\text { odds ratio }
\end{aligned}
\end{aligned}
$$

Congenital Heart Surgeons Society have not demonstrated gender differences in surgical outcome for a variety of operations to correct specific kinds of congenital heart disease, including transposition of the great arteries, ${ }^{9,10}$ atrioventricular septal defects and atrioventricular canal, ${ }^{11,12}$ hypoplastic left heart syndrome and other forms of singleventricle physiology, ${ }^{13-16}$ aortic stenosis or atresia, ${ }^{17,18}$ and aortic arch interruption. ${ }^{19}$ However, these studies were subject to a variety of limitations, including potential selection biases, relatively small sample sizes, and limited ability to adjust for potential gender-procedure interactions. Only one study, by Chang and colleagues ${ }^{20}$ evaluated a relatively large number of inpatient hospital records that encompassed all significant congenital heart operations with the intent to ascertain a gender effect on outcome. Although females were found to have higher odds of death, the study was limited to a single region, did not consider low-volume hospitals, and was restricted in the number of procedures per each hospital discharge evaluated. The effect of these limitations on the risk estimation is unknown. The objective of the current study is to determine whether the risk-adjusted probability of in-hospital mortality is higher for female pediatric patients undergoing cardiac surgery and to identify factors associated with any difference in outcome, studying a wider set of covariates with a larger data set.

\section{Materials and Methods}

This study was approved by the Committee on Safety of Human Subjects of the Children's Hospital of Philadelphia.

\section{Data Source}

The Healthcare Cost and Utilization Project (HCUP) Kids' Inpatient Database (KID) ${ }^{21}$ contains information from a nationwide sample of pediatric discharges from community hospitals in states that provided inpatient discharge data to statewide agencies. The KID sampling frame consists of all US short-term, nonfederal, general, and specialty hospitals that had pediatric discharges in the 27 participating state databases for the year 2000. Ten percent of uncomplicated births and $80 \%$ of other hospitalizations for children 20 years and younger at the time of hospital admission were sampled from all hospitals in the sampling frame. KID contains information on more than 2.5 million pediatric discharges from more than 2700 hospitals. Discharge weights are provided with the KID and can be used to obtain national estimates of hospitalizations within the United States. Detailed information on the design of the KID is available in the special report on Design of the
Kids' Inpatient Database, 2000, found on the KID Documentation CD-ROM. The KID data include more than 115 clinical and nonclinical variables for each hospital stay, including primary and ancillary diagnoses, up to 15 procedures per hospitalization, admission and discharge status, patient demographics (eg, gender, age, race, and median income for home zip code), expected payment source, total charges, and length of stay. Hospital characteristics, such as location (census region, urban, or rural), size (number of beds), and teaching status, are also specified in the KID data.

\section{Case Selection}

We studied information from discharges with at least one International Classification of Diseases, Ninth Revision, Clinical Modification procedure code, which indicates surgical procedures for repair of congenital heart disease. In addition, to identify hospitalizations during which a Norwood procedure was performed, we included information from records that contained both a diagnosis code of hypoplastic left heart syndrome (74.67) and a procedure code of cardiopulmonary bypass (39.61). For consistency with other classification schemes, we excluded closure of patent ductus arteriosis from our analysis. ${ }^{20,22}$

\section{Study Variables and Risk Analysis}

In-hospital death, identified by the discharge status in the KIDS data set, was used as the main outcome variable. The unadjusted odds ratio (OR) for each putative risk factor was initially evaluated in the univariate analysis. To adjust for the effects of other risk factors and potential confounding factors on each putative risk factor, we then performed multivariate logistic regression analyses that included patient-related, health care system-related, and clinical factors as independent variables. In our analysis, each independent variable was divided into mutually exclusive subgroups to characterize each hospitalization. In addition to gender, the patient-related variables included age, race/ethnicity, and family income (by median household income of the patient's home zip code). Health care system-related variables included the calendar quarter of admission, number of days between admission and operation, type of admission, source of admission, type of insurance, hospital teaching status, hospital case volume for pediatric heart surgery, and state in which the hospital was located. Medical variables included the type of primary procedure and the presence or absence of each of 4 comorbidities. Because pediatric cardiac surgery is composed of a large variety of different procedures, and some procedures are rarely performed, it is usually impossible to perform meaningful analysis considering each type of operation separately. Therefore, several algorithms have been developed, generally by expert opinion, to group similar operations into categories. We used a modification of Chang and colleagues' ${ }^{20}$ refinement of Ericson and colleagues' classification scheme, ${ }^{23}$ and classified each operation into 1 of 21 mutually exclusive groups (Table 1). To determine which procedure was classified for each discharge, we examined all of the 15 or fewer procedures listed in each discharge record. Each record was assigned to 1 of the 21 procedure groups. For consistency with a previous model of mortality after cardiac surgery, ${ }^{20}$ we also included 4 comorbidities as independent, nonprocedural variables: Down syndrome (International Classification of Diseases, Ninth Revision, Clinical Modi- 
TABLE 1. Characteristics of records with International Classification of Diseases, Ninth Revision, Clinical Modification codes for cardiac operations in the Kids' Inpatient Database 2000 data set $^{21}$

\begin{tabular}{|c|c|c|c|c|}
\hline Variable & Records (No.) & Deaths (No.) & Mortality (\%) & Unadjusted, univariate probability*- \\
\hline Total & 10,282 & 474 & 4.50 & \\
\hline Sex & & & & .466 \\
\hline Male & 5589 & 250 & 4.44 & \\
\hline Female & 4692 & 224 & 4.56 & \\
\hline \multicolumn{5}{|l|}{ Age } \\
\hline Neonate & 1364 & 199 & 15.23 & .009 \\
\hline Infant & 2100 & 75 & 3.23 & $<.001$ \\
\hline Child & 5359 & 71 & 1.15 & $<.001$ \\
\hline \multicolumn{5}{|l|}{ Race } \\
\hline White & 4516 & 178 & 3.90 & .004 \\
\hline Black & 1004 & 62 & 5.93 & .013 \\
\hline Hispanic & 1897 & 96 & 5.01 & .300 \\
\hline Other & 2498 & 127 & 4.9 & .194 \\
\hline \multicolumn{5}{|l|}{ Insurance } \\
\hline Private & 5352 & 222 & 4.11 & .069 \\
\hline Medicaid & 3574 & 177 & 4.86 & .113 \\
\hline Other insurance & 540 & 23 & 4.26 & .916 \\
\hline Uninsured & 406 & 21 & 4.05 & .690 \\
\hline \multicolumn{5}{|c|}{ Median annual income for patient's zip code } \\
\hline$\$ 1-\$ 24,999$ & 934 & 31 & 3.07 & .315 \\
\hline$\$ 25,000-\$ 34,999$ & 2589 & 138 & 5.2 & .043 \\
\hline$\$ 35,000-\$ 44,999$ & 2551 & 125 & 4.75 & .420 \\
\hline$>\$ 45,000$ & 3747 & 154 & 4.04 & .067 \\
\hline \multicolumn{5}{|l|}{ Month of operation } \\
\hline January-March & 2166 & 106 & 4.91 & .478 \\
\hline April-June & 2490 & 98 & 3.80 & .065 \\
\hline July-September & 2628 & 121 & 4.51 & .987 \\
\hline October-December & 2113 & 92 & 4.14 & .529 \\
\hline Day of operation & & & & $<.001$ \\
\hline Weekday & 9499 & 397 & 4.06 & \\
\hline Weekend & 783 & 77 & 9.8 & \\
\hline Source of admission & & & & .309 \\
\hline Non-emergency & 9855 & 450 & 4.46 & \\
\hline Emergency & 427 & 24 & 5.38 & \\
\hline Type of admission & & & & $<.001$ \\
\hline Elective & 4934 & 97 & 1.79 & \\
\hline Non-elective & 5248 & 377 & 7.11 & \\
\hline \multicolumn{5}{|l|}{ Cardiac surgery volume } \\
\hline Lowest tertile & 2479 & 116 & 4.60 & .570 \\
\hline Middle tertile & 2595 & 124 & 4.82 & .018 \\
\hline Highest tertile & 2654 & 99 & 3.66 & .003 \\
\hline \multicolumn{5}{|l|}{ Comorbidity } \\
\hline Down syndrome & 794 & 18 & 2.03 & .001 \\
\hline Pulmonary hypertension & 359 & 32 & 9.00 & .001 \\
\hline Prematurity & 43 & 2 & 4.58 & $<.001$ \\
\hline Failure to thrive & 425 & 7 & 1.65 & .003 \\
\hline \multicolumn{5}{|l|}{ Type of procedure } \\
\hline Aortopulmonary shunt & 1154 & 170 & 14.73 & $<.001$ \\
\hline Aortic valve replacement & 219 & 8 & 3.03 & .069 \\
\hline Arterial switch & 454 & 32 & 8.04 & .011 \\
\hline Atrial septal defect closure & 1643 & 10 & 0.61 & $<.001$ \\
\hline Atrial switch & 138 & 7 & 5.07 & .794 \\
\hline Atrioventricular canal defect repair & 697 & 31 & 4.45 & .832 \\
\hline Cavopulmonary shunt & 617 & 16 & 2.59 & .014 \\
\hline
\end{tabular}


TABLE 1. Continued

\begin{tabular}{|c|c|c|c|c|}
\hline Variable & Records (No.) & Deaths (No.) & Mortality (\%) & Unadjusted, univariate probability* + \\
\hline Fontan operation & 551 & 19 & 3.45 & .181 \\
\hline Infundibulectomy & 105 & 1 & 0.95 & .072 \\
\hline Mitral valve replacement & 141 & 10 & 7.09 & .157 \\
\hline Norwood & 318 & 67 & 21.07 & $<.001$ \\
\hline Orthotopic heart transplant & 155 & 9 & 5.81 & .474 \\
\hline Resection of subaortic membrane & 108 & 1 & 0.93 & .066 \\
\hline Right ventricle to pulmonary artery conduit & 228 & 11 & 4.82 & .876 \\
\hline Thoracic vessel repair & 679 & 40 & 5.89 & .010 \\
\hline Tetralogy of Fallot repair & 809 & 31 & 3.83 & .272 \\
\hline Total anomalous pulmonary venous return repair & 320 & 31 & 9.69 & \\
\hline Tricuspid or pulmonary valve replacement & 478 & 13 & 2.63 & .044 \\
\hline Truncus arteriosus repair & 130 & 13 & 9.7 & .003 \\
\hline Open valvuloplasty & 850 & 23 & 2.71 & .006 \\
\hline Ventricular septal defect repair & 1275 & 39 & 3.06 & .005 \\
\hline
\end{tabular}

*Chi-square statistic. †For each variable, the number of records in each stratum was compared with sum of the number of records in all other strata.

fication code 758.0), failure to thrive (783.4), prematurity (765.0 and 765.1), and pulmonary hypertension (416.0).

\section{Data Analysis}

Logistic regression analyses were used to determine whether gender is an independent risk factor for in-hospital death after pediatric cardiac surgery. For all analyses, the only dependent variable was a dichotomous (binary) outcome variable: alive at discharge versus in-hospital death. For each categoric independent variable, 1 subgroup was designated as the reference $(\mathrm{OR}=1)$ to calculate the OR for mortality for the other subgroups relative to the reference subgroup. The reference subgroups were as follows: male for "sex," child (age $\geq 1$ year) for "age," white for "race," public insurance for "type of insurance," October to December for "month of surgery," non-emergency room admission for "source of admission," emergency admission for "type of admission," ventricular septal defect closure for "type of operation," California for "state," median annual family income of $\$ 1$ to $\$ 24,999$ for "family income by ZIP code," absence of comorbidity for each of the 4 comorbidity variables, nonteaching for "hospital teaching status," and no for "birth during hospitalization." We included variables representing the number of procedures performed on the patient and the percentage of the admitting hospital's discharges that were pediatric; these 2 continuous variables were categorized into quartiles with the lowest quartile serving as the reference group. Finally we included a hospital-level variable representing the average of the "weights" for each of the diagnosis-related groups (DRGs) associated with each patient in that hospital. These "weights" are calculated by the federal government to help determine reimbursement rates and are based on estimated resource use; this is a marker for severity of illness. Hospitals with a high average DRG weight will necessarily have a greater proportion of severely ill patients; the purpose of including a hospital-level variable representing the average DRG weight is to take into account the differences in case-mix between the hospitals that admitted the patients in our sample. Procedures were encoded as mutually exclusive binary variables, so that each discharge record would only indicate 1 procedure (ie, each hospitalization could have only 1 value of " 1 " among the 21 operation types). The results of risk determinations for each group of variables are presented as ORs comparing each subgroup with its respective reference subgroup. For each OR, the 95\% confidence interval (CI) and $P$ value are presented.

We constructed several logistic regression models: Our first logistic regression model was designed to determine whether females had a different probability of in-hospital mortality after cardiac surgery and to identify significant risk factors for any such difference. A second logistic regression model evaluated the possible effects of age and different types of operations by adding an interaction term for each age-operation pair. We then assessed the possible effects of gender by adding to the original model an interaction term for each gender-procedure pair. Additional analyses examined whether gender differences in mortality were associated with differences in health care use by comparing length of stay and total hospital charges between males and females. Regressions were performed with and without adjustment for clustering by medical center, and the results were compared. Bootstrapping was used to estimate the internal validity of the primary model, that is, its accuracy in the overall population from which this sample was taken. ${ }^{24}$ All calculations were performed with STATA 8.0 (Stata Corporation, College Park, Tex).

\section{Results}

We identified 10,282 hospitalizations during which at least 1 of the 21 types of heart surgeries was performed. The overall risk of death during these hospitalizations was $4.50 \%(\mathrm{n}=474)$. Table 1 lists the descriptive statistics of our cohort, along with univariate analyses of their effects of mortality. In the unadjusted, univariate analysis, females do not seem to be at greater risk of death than males (chisquare 0.53 , OR 1.07, exact 95\% CI 0.89-1.29, $P=.4656$ ). This estimate ignores all other factors, such as differences in age distributions between males and females.

The results of the multivariate logistic regression model are shown in Table 2. This analysis provides an estimate of 
TABLE 2. Results of logistic regression for in-hospital death

\begin{tabular}{|c|c|c|c|}
\hline Variable & OR & $\begin{array}{l}\text { Two-sided, } \\
95 \% \mathrm{Cl}\end{array}$ & $\begin{array}{c}P \\
\text { value }\end{array}$ \\
\hline \multicolumn{4}{|l|}{ Sex } \\
\hline Female & 1.31 & $1.02-1.69$ & .036 \\
\hline \multicolumn{4}{|l|}{$\begin{array}{l}\text { Time between admission and } \\
\text { operation }\end{array}$} \\
\hline Same day operation & 0.71 & $0.51-0.99$ & .043 \\
\hline $\begin{array}{l}\text { Each additional day between } \\
\text { admission and operation }\end{array}$ & 1.01 & $1.00-1.02$ & .002 \\
\hline \multicolumn{4}{|l|}{ Age group } \\
\hline Neonate & 3.79 & $2.25-6.40$ & $<.001$ \\
\hline Infant & 2.78 & $1.88-4.12$ & $<.001$ \\
\hline \multicolumn{4}{|l|}{ Race or ethnicity } \\
\hline Black & 1.64 & $1.14-2.35$ & .007 \\
\hline Hispanic & 1.16 & $0.85-1.57$ & .349 \\
\hline Asian & 0.70 & $0.32-1.53$ & .367 \\
\hline Other races & 1.19 & $0.85-1.67$ & .297 \\
\hline \multicolumn{4}{|l|}{ Insurance } \\
\hline Uninsured & 1.08 & $0.60-1.96$ & .796 \\
\hline Medicaid & 0.82 & $0.64-1.05$ & .120 \\
\hline Other insurance & 0.74 & $0.40-1.35$ & .321 \\
\hline \multicolumn{4}{|l|}{ Month of admission } \\
\hline January-March & 1.37 & $0.98-1.91$ & .066 \\
\hline April-June & 1.10 & $0.76-1.61$ & .603 \\
\hline July-September & 1.35 & $0.99-1.85$ & .061 \\
\hline \multicolumn{4}{|l|}{ Source of admission } \\
\hline Emergency department admission & 0.70 & $0.43-1.15$ & .159 \\
\hline \multicolumn{4}{|l|}{ Type of admission } \\
\hline Elective admission & 0.51 & $0.35-0.75$ & .001 \\
\hline \multicolumn{4}{|l|}{ Procedure } \\
\hline Aortic valve replacement & 1.31 & $0.54-3.16$ & .549 \\
\hline Aortopulmonary shunt & 2.79 & $1.85-4.10$ & $<.001$ \\
\hline Arterial switch & 1.33 & $0.77-2.28$ & .307 \\
\hline Atrial septal defect closure & 0.52 & $0.27-1.01$ & .054 \\
\hline Atrial switch & 2.79 & $0.87-9.00$ & .085 \\
\hline Cavopulmonary shunt & 0.63 & $0.36-1.12$ & .115 \\
\hline Fontan operation & 1.41 & $0.74-2.70$ & .295 \\
\hline Mitral valve replacement & 4.20 & $1.97-8.98$ & $<.001$ \\
\hline Norwood procedure & 1.89 & $1.32-2.71$ & .001 \\
\hline Orthotopic heart transplant & 1.57 & $0.67-3.64$ & .295 \\
\hline $\begin{array}{l}\text { Repair of complete atrioventricular } \\
\text { canal }\end{array}$ & 2.28 & $1.33-3.89$ & .003 \\
\hline $\begin{array}{l}\text { Repair of total anomalous } \\
\text { pulmonary venous return }\end{array}$ & 2.37 & $1.41-3.99$ & .001 \\
\hline $\begin{array}{l}\text { Right ventricle to pulmonary artery } \\
\text { shunt }\end{array}$ & 4.20 & $1.73-10.17$ & .002 \\
\hline Subaortic membrane resection & 0.46 & $0.57-3.68$ & .460 \\
\hline Tetralogy of Fallot repair & 0.91 & $0.44-1.87$ & .797 \\
\hline Thoracic vessel repair & 1.77 & $1.14-2.76$ & .012 \\
\hline Tricuspid valve replacement & 1.14 & $0.52-2.53$ & .743 \\
\hline Truncus arteriosis repair & 1.64 & $0.70-3.84$ & .249 \\
\hline Valvuloplasty & 1.24 & $0.69-2.23$ & .471 \\
\hline \multicolumn{4}{|l|}{ Median household income by zip code } \\
\hline$\$ 25,000-\$ 34,999$ & 2.04 & $1.10-3.77$ & .024 \\
\hline$\$ 35,000-\$ 44,999$ & 2.00 & $1.06-3.77$ & .032 \\
\hline$>\$ 45,000$ & 1.92 & $1.00-3.72$ & .050 \\
\hline
\end{tabular}

TABLE 2. Continued

\begin{tabular}{|c|c|c|c|}
\hline Variable & OR & $\begin{array}{l}\text { Two-sided, } \\
\text { 95\% Cl }\end{array}$ & $\begin{array}{c}P \\
\text { value }\end{array}$ \\
\hline \multicolumn{4}{|l|}{ State } \\
\hline Arizona & 2.89 & $1.50-5.56$ & .002 \\
\hline Colorado & 0.89 & $0.38-2.06$ & .779 \\
\hline Connecticut & 5.06 & $2.55-10.03$ & $<.001$ \\
\hline Florida & 4.85 & $2.58-9.09$ & $<.001$ \\
\hline lowa & 0.24 & $0.12-0.48$ & $<.001$ \\
\hline Kentucky & 2.00 & $0.91-4.40$ & .086 \\
\hline Mass & 0.67 & $0.32-1.44$ & .308 \\
\hline Maryland & 0.57 & $0.31-1.06$ & .074 \\
\hline Maine & 0.45 & $0.23-0.89$ & .022 \\
\hline Missouri & 1.02 & $0.33-3.12$ & .979 \\
\hline North Carolina & 0.90 & $0.52-1.54$ & .703 \\
\hline New Jersey & 1.29 & $0.35-4.71$ & .702 \\
\hline New York & 0.80 & $0.48-1.35$ & .405 \\
\hline Oregon & 0.66 & $0.33-1.31$ & .237 \\
\hline Pennsylvania & 1.01 & $0.52-1.97$ & .975 \\
\hline South Carolina & 4.89 & $2.71-8.85$ & $<.001$ \\
\hline Tennessee & 1.56 & $0.85-2.83$ & .148 \\
\hline Virginia & 1.09 & $0.44-2.71$ & .855 \\
\hline Wisconsin & 0.96 & $0.22-4.08$ & .951 \\
\hline \multicolumn{4}{|l|}{ Comorbidity } \\
\hline Down syndrome & 0.44 & $0.21-0.94$ & .033 \\
\hline Pulmonary hypertension & 1.74 & $1.11-2.71$ & .015 \\
\hline Failure to thrive & 0.46 & $0.20-1.02$ & .056 \\
\hline Prematurity & 1.37 & $0.77-2.41$ & .281 \\
\hline \multicolumn{4}{|l|}{ Day of operation } \\
\hline Weekend & 1.06 & $0.76-1.49$ & .731 \\
\hline \multicolumn{4}{|c|}{ Volume of pediatric cardiac surgery } \\
\hline Middle tertile & 0.68 & $0.46-1.00$ & .049 \\
\hline Highest tertile & 0.50 & $0.35-0.71$ & $<.001$ \\
\hline \multicolumn{4}{|c|}{$\begin{array}{l}\text { No. of procedures performed during } \\
\text { hospitalization }\end{array}$} \\
\hline Second quartile & 0.77 & $0.30-2.01$ & .594 \\
\hline Third quartile & 2.04 & $0.72-5.78$ & .176 \\
\hline Fourth quartile & 3.86 & $1.70-8.79$ & .001 \\
\hline Hospital birth & 1.44 & $0.94-2.21$ & .093 \\
\hline DRG weight & 1.02 & $0.89-1.18$ & .774 \\
\hline
\end{tabular}

Percentage of hospital discharges that were pediatric (ie, patient aged $<20$ y at admission)

Second quartile

$\begin{array}{lll}0.82 & 0.52-1.28 \quad .384\end{array}$

Third quartile

Fourth quartile

$0.58 \quad 0.31-1.08 \quad .086$

Hospital teaching status

$0.73 \quad 0.43-1.23 \quad 236$

Teaching

$1.50 \quad 0.92-2.42 \quad .100$

$O R$, Odds ratio; $C l$, confidence interval; $D R G$, diagnosis-related group.

the risk of death for females, compared with males, taking into account all of the other covariates. The area under the receiver operator characteristic curve was 0.845 , indicating that the regression model was excellent at distinguishing the outcomes between survival and in-hospital death. 
Female gender was associated with increased risk of in-hospital death when all of the other measured factors were taken into consideration. In addition to gender, factors that were significantly associated with increased in-hospital mortality after pediatric cardiac surgery included the number of days between admission and operation; AfricanAmerican race; young age (neonates and infants, when each group is compared with children aged $\geq 1$ year); and pulmonary hypertension. Down syndrome and elective admission were associated with a lower odds of mortality. There were also significant differences among the types of operations and different states, and among calendar quarters (higher risk in the first and third quarters of the year).

To evaluate whether the apparent increased risk associated with a female gender could have been explained by a significant difference in risk for a given procedure that was insufficiently captured by our original model, we performed additional analyses of the effect of age and gender, respectively, on the risk of death by using additional terms for the gender-age or gender-procedure interaction for each of the 21 categories of procedure. The addition of gender-age interaction terms produced a significant gender difference in mortality only for children aged more than 1 year (OR 0.35 , $P<.001)$. The only factor for which a new gender effect on mortality was revealed by the added gender-procedure interaction terms was tricuspid valve repair (OR 8.76, $P=$ .009). Bootstrapping produced risk estimates for each factor that were not statistically different from the primary model, thus confirming the model's internal validity.

Neither total charges nor length of stay was significantly different between males and females when all of the other factors were taken into consideration.

\section{Discussion}

We found that female gender was associated with a significantly higher risk of in-hospital mortality among a national sample of children undergoing surgery for congenital heart disease in the year 2000. This difference was probably not due to variations in resource use during hospitalization, because the risk-adjusted length of stay and total charges were not significantly different between the genders. We also found that the time between admission and operation, patient age, African American race, and the presence of pulmonary hypertension were important factors in determining mortality. As expected, there were also differences in risk among the states in which the operations were performed and among the types or operations.

The crude, unadjusted analysis showed a small, statistically insignificant difference in in-hospital mortality between females and males. However, this difference became significant after adjustment for patient-related, health services-related, and clinical factors.
Most studies of mortality after surgery for congenital heart disease have not identified a gender difference. Jenkins and colleagues ${ }^{22}$ did not find that gender was associated with increased probability of in-hospital mortality. Hannan and colleagues ${ }^{25}$ did not report the risk-adjusted probability of mortality, although the crude mortality risk in their study was calculated by Chang and colleagues ${ }^{20}$ to be slightly higher for males. A difference in mortality for males and females was identified by Chang and colleagues, ${ }^{20}$ who found a significantly greater risk for females in a 3-year cohort of discharge data from California. However, this study was subject to several methodologic limitations, including a sample that was derived from a single state (ie, California), the exclusion of data from hospitals that performed fewer than 10 operations during the study period, and consideration of only the first 5 procedures for each record to determine the operation by which each record was classified.

Among adults undergoing coronary artery bypass surgery, females have higher operative, in-hospital, and longterm mortality, and are at greater risk of postoperative morbidity. ${ }^{1-3}$ The explanations for females having worse outcomes have generally addressed possible differences in biology and medical care. Biological factors associated with female gender and worse outcome include greater age at operation and higher prevalence of diabetes mellitus, hypertension, renal insufficiency, and moderate obesity. Women also tend to have smaller coronary arteries and may have different endovascular endothelial physiology and plaque pathophysiology. Differences in medical care include less likelihood of receiving thrombolytic therapy and cardiac catheterization, frequent gender-based referral bias for coronary artery bypass surgery, and greater probability of requiring readmission after discharge following coronary artery bypass grafting. Of course, none of these apply to our study population. In the current study, we assessed inhospital health care resource use by comparing risk-adjusted total charges. These did not differ significantly between males and females, suggesting that service use was not different. Because we assessed in-hospital mortality, an apparent lower risk of death for males could have been caused by earlier discharge of males, which would artificially reduce their "time at risk." However, the risk-adjusted length of stay was comparable for females and males. Our ability to consider biologic factors was somewhat limited by the data source and sample size. We considered 4 comorbidities and found that pulmonary hypertension was associated with a higher risk of mortality and that Down syndrome was associated with a lower risk of mortality, whereas premature birth and failure to thrive were not significantly associated with the risk of death. Pulmonary hypertension has been well established as a determinant of perioperative morbidity and mortality after operations to 
repair congenital heart disease. ${ }^{26}$ The effect of Down syndrome on immediate outcome is less clear. Previous studies identified increased risk of mortality after repair of ventricular septal defects ${ }^{27}$ or atrioventricular canal, ${ }^{28}$ but they were limited by small sample sizes and little, if any, risk adjustment. However, it is also possible the differences in survival identified in our study are due to other comorbid conditions and biological factors that were not characterized in this administrative data set.

Neonates and infants had significantly higher risks of mortality than older children. Although the frequencies of the different types of surgery differed among age groups, adjustment for these differences did not eliminate agerelated differences in mortality. When adjusted for the other factors in our model, the OR of death was 3.79 for neonates (95\% CI 2.25-6.39) and 2.78 for infants $(95 \%$ CI 1.88-4.12) compared with children aged 1 year or more. These ORs are consistent with those reported by other investigators. ${ }^{20,23}$

African-American adults have a higher risk of mortality after coronary artery bypass graft surgery, possibly because of increased frequencies of comorbid conditions and less access to care. ${ }^{29,30}$ In contrast, significant racial and ethnic differences in mortality after cardiac surgery in children have been identified in some studies ${ }^{29}$ but not others. ${ }^{20,23}$ We found that risk-adjusted odds of mortality were 1.64 (95\% CI 1.14-2.35) times higher for African Americans than for whites. A significantly increased risk of mortality for other racial groups was not found.

Elective admissions were associated with approximately half the mortality risk (OR $0.51,95 \%$ CI $0.35-0.75$ ) of emergency admissions. Because this difference was observed after adjustment for age, type of operation, and socioeconomic factors, it is likely that this association could be due to unmeasured comorbidities or severity of illness.

The time between admission and operation was also significantly associated with mortality. Surgery on the same day as hospital admission was associated with a lower risk-adjusted mortality (OR 0.71, 95\% CI 0.51-0.99). Each successive day's delay between admission and surgery was associated with a slight, but statistically significant, increase in adjusted risk (OR 1.01, 95\% CI 1.00-1.02). Although the factors responsible for the increased mortality risk associated with delays between admission and operation are not represented in our model, one could hypothesize that similar factors affecting the risks associated with non-elective admissions were also associated with this parameter.

The association of larger case volumes and lower mortality for pediatric cardiac surgery has been shown by at least 3 previous studies. Jenkins and colleagues ${ }^{22}$ found that, compared with centers that performed more than 300 operations annually, the risk-adjusted OR for mortality was 7.7 at centers that performed fewer than 10 operations annually and approximately 3.0 at centers that performed between 10 and 300 operations annually. Hannan and colleagues $^{25}$ and Chang and colleagues ${ }^{20}$ demonstrated an increased probability of risk-adjusted mortality at centers that performed fewer than 100 operations per year compared with centers performing more operations. Our results show successively decreasing mortality in each successive tertile of case volume.

The major limitations of this study relate to the types and quality of data available for analysis. Miscoding can occur in administrative databases. To protect patient confidentiality, data in HCUP databases cannot be validated by comparing them with the source documents (hospital records) from which they are derived. To assess the potential impact of miscoding, we reviewed the procedure and diagnosis codes of a random sample of $20 \%$ of records with fatal outcome, and the same number of nonfatal cases. No cases were encountered in which the procedure and diagnosis codes were inconsistent. However, the potential effects of missing information cannot be assessed. It is also possible that a patient could undergo operation, be discharged, then readmitted and undergo reoperation during the 1-year span of our data. In such situations, the outcome of the second admission and operation could not be linked to the first. We believe that this situation is relatively infrequent, on the basis of our clinical experience, the relatively short time window during which the sample was obtained, and a single published series. ${ }^{31}$ Therefore, it is unlikely that this substantially affected our results.

An important limitation of previous studies has been the use of multiple years of data to increase sample size, thus introducing unknown influences over time. Observations contained in KID were acquired from a single year, minimizing the influence of time-related biases. Outcomes can differ by geographic region, but this effect should be minimal in KID, which sampled from 27 states. There were statistically significant differences in mortality among the states, which was important to consider in the risk adjustment for our model. However, because of the limited time window (ie, 1 year) for which data were obtained, and differences in sampling among states, it is possible that this information is sufficiently biased to prevent meaningful comparisons of mortality risks among states.

Subtle associations are difficult to identify within small data sets. Our analysis was based on the largest, most contemporary data set that was created for health services research. It is also possible that more males died after transfer to hospitals that did not participate in HCUP programs, or were discharged, readmitted, and died. Although it is not possible to prove that this did not happen, our clinical experience is that these are not common scenarios and therefore are unlikely to have a significant effect on the overall risk estimate. Finally, in-hospital mortality can arise 
from many causes, some of which may be unrelated to surgical factors.

\section{Conclusions}

Female gender was associated with an increased risk of in-hospital death after pediatric cardiac surgery. In our national sample, the risk of mortality was $31 \%$ greater for females, when patient-related, health care system-related, and clinical factors were simultaneously considered. The differences in outcomes do not seem to be related to health services use. Future studies should be directed at identifying and characterizing the biological factors that may account for this difference in survival. ${ }^{30}$

\section{References}

1. Edwards FH, Carey JS, Grover FL, Bero JW, Hartz RS. Impact of gender on coronary bypass operative mortality. Ann Thorac Surg. 1998;66:125-31.

2. Koch CG, Khandwala F, Nussmeier N, Blackstone EH. Gender and outcomes after coronary artery bypass grafting: a propensity matched comparison. J Thorac Cardiovasc Surg. 2003;126:2032-43.

3. Vaccarino V, Abramson JL, Veledar E, Weintraub WS. Sex differences in hospital mortality after coronary artery bypass surgery. Evidence for a higher mortality in younger women. Circulation. 2002; 105:1176.

4. Hassold T, Quillen SD, Yamane JA. Sex ratio in spontaneous abortions. Ann Hum Genet. 1983;47(Pt 1):39-47.

5. Ingemarsson I. Gender aspects of preterm birth. Br J Obstet Gynaecol. 2003;110(suppl 20):34-8.

6. Khoury MJ, Marks JS, McCarthy BJ, Zaro SM. Factors affecting the sex differential in neonatal mortality: the role of respiratory distress syndrome. Am J Obstet Gynecol. 1985;151:777-82.

7. Ingemarsson I, Herbst A, Thorngren-Jerneck K. Long term outcome after umbilical artery acidaemia at term birth: influence of gender and duration of foetal heart rate abnormalities. Br J Obstet Gynaecol. 1997;104:1123-7.

8. Centers for Disease Control and Prevention (CDC). Trends in infant mortality attributable to birth defects-United States, 1980-1995. MMWR Morb Mortal Wkly Rep. 1998;47:773-8.

9. Castaneda AR, Trusler GA, Paul MH, Blackstone EH, Kirklan JW. The early results of treatment of simple transposition in the current era. J Thorac Cardiovasc Surg. 1988;95:14-28.

10. Williams WG, McCrindle BW, Ashburn DA, Jonas RA, Mavroudis C, Blackstone EH, et al. Outcomes of 829 neonates with complete transposition of the great arteries 12-17 years after repair. Eur J Cardiothorac Surg. 2003;24:1-10.

11. Schaffer R, Berdat P, Stolle B, Pfammatter JP, Stocker F, Carrel T. Surgery for complete atrioventricular canal: relationship between age at operation, mitral regurgitation, size of the ventricular septal defect, additional malformations and early postoperative outcome. Cardiology. 1999;91:231-5.

12. Tweddell JS, Litwin SB, Berger S, Friedberg DZ, Thomas JP, Frommelt PC, et al. Twenty-year experience with repair of complete atrioventricular septal defects. Ann Thorac Surg. 1996;62:419-24.

13. Mahle WT, Spray TL, Wernovsky G, Gaynor JW, Clark BJ III. Survival after reconstructive surgery for hypoplastic left heart syndrome. A 15-year experience from a single institution. Circulation. 2000;102(suppl III):III136-41.
14. Gaynor JW, Mahle WT, Cohen MI, Ittenbach RF, DeCampli WM, Steven JM, et al. Risk factors for mortality after the Norwood procedure. Eur J Cardiothorac Surg. 2002;22:82-9.

15. Mahle WT, Spray TL, Wernovsky G, Gaynor JW, Clark BJ III. Survival after reconstructive surgery for hypoplastic left heart syndrome. A 15-year experience from a single institution. Circulation. 2000;102(suppl III):III136-41.

16. Gentles TL, Mayer JE, Gauvreau K, Newberger JW, Lock JE, Kupferschmid JP, et al. Fontan operation in five hundred consecutive patients: factors influencing early and late outcome. J Thorac Cardiovasc Surg. 1997:114:376-91.

17. Lofland GK, McCrindle BW, Williams WG, Blackstone EH, Tchervenkov CI, Sittiwangkul R, et al. Critical aortic stenosis in the neonate: a multiinstitutional study of management, outcomes, and risk factors. J Thorac Cardiovasc Surg. 2001;121:10-27.

18. Ashburn DA, McCrindle BW, Tchervenkov CI, Jacobs ML, Lofland GK, Bove EL, et al. Outcomes after the Norwood operation in neonates with critical aortic stenosis or aortic valve atresia. $J$ Thorac Cardiovasc Surg. 2003;121:10-27.

19. Jonas RA, Quaegebeur JM, Kirklan JW, Blackstone EH, Daicoff G. Outcomes in patients with interrupted aortic arch and ventricular septal defect: a multiinstitutional study. J Thorac Cardiovasc Surg. 1994; 107:1099-113.

20. Chang R-K, Chen AY, Klitzner TS. Female sex as a risk factor for in-hospital mortality among children undergoing cardiac surgery. Circulation. 2002;106:1514-22.

21. HCUP Kids' Inpatient Database (KID). Healthcare Cost and Utilization Project (HCUP), 2000. Agency for Healthcare Research and Quality, Rockville, MD. www.hcup-us.ahrq:gov/kidoverview.jsp

22. Jenkins KJ, Gauvereau K, Newberger JW, Spray TL, Moller JH, Iezzoni LL. Consensus-based method for risk adjustment for surgery for congenital heart disease. J Thorac Cardiovasc Surg. 2002; 123:110-18

23. Ericson LC, Wise PH, Cook EF, Beiser A, Newberger JW. The impact of managed care insurance on use of lower-mortality hospitals by children undergoing cardiac surgery in California. Pediatrics. 2000; 105:1271-8.

24. Steyerberg EW, Harrell FE, Borsboom GJJM, Eijkemans MJC, Vergouwe Y, Habbema JDF. Internal validation of predictive models: efficiency of some procedures for logistic regression analysis. $J$ Clin Epidemiol. 2001;54:774-81.

25. Hannan EL, Racz M, Kavey RE. Pediatric cardiac surgery: the effect of hospital and surgeon volume on in-hospital mortality. Pediatrics. 1998;101:963-9.

26. Bando K, Turrentine MW, Sharp TG, Sekine Y, Aufiero TX, Sun K, et al. Pulmonary hypertension after operations for congenital heart disease: analysis of risk factors and management. J Thorac Cardiovasc Surg. 1996;112:1600-9.

27. Morray JP, MacGillivray R, Duker G. Increased perioperative risk following repair of congenital heart disease in Down's syndrome. Anesthesiology. 1986;65:221-4.

28. Reller MD, Morris CD. Is Down syndrome a risk factor for poor outcome after repair of congenital heart defects? J Pediatr. 1998;132: 738-41.

29. Bridges CR. Cardiac surgery in African Americans. Ann Thorac Surg. 2003;76:S1356-62

30. Gonzales PC, Gauvereau K, DeMone JA, Piercey GE, Jenkins KJ. Regional racial and ethnic differences in mortality for congenital heart surgery in children may reflect unequal access to care. Pediatr Cardiol. 2003;24:103-8.

31. Monro JL, Alexiou C, Salmon AP, Keeton BR. Reoperations and survival after primary repair of congenital heart defects in children. J Thorac Cardiovasc Surg. 2003;126:511-19. 